\title{
Do responsiveness and accountability matter at the municipal level?
}

In theory, two processes guarantee the principle of democratic representation: elected officials' responsiveness to citizens' preferences on the one hand and accountability on the other (Gerstlé, 2003). Democratic theory suggests that elected representatives should implement the preferred policies of voters. For their part, voters are to reward or punish elected representatives based on the correspondence between the performance of government action and citizens' expectations. Elections present an ideal, and often the only, opportunity for this evaluation.

While national level studies have shown how the balance between these two processes and the principle of democratic representation is realized (Pétry, 1999; Stimson et al., 1995; Erickson et al., 1993; Lax and Phillips, 2012), opposite conclusions have been drawn at the municipal level. The local context presents many economic, political or legislative constraints with regard to the responsiveness of elected representatives, making achieving a balance between citizens' preferences and policy difficult (Gerber and Hopkins, 2011; Leigh, 2008; Nivola, 2002; Petersen, 1981; Rae, 2003; Self, 2003). For some researchers, if and when such a balance exists, it can be attributed to fiscal federalism (Tiebout, 1956) or to path dependency (Collin and Hamel, 1993). However, these conclusions there are merely speculative in nature, as they are based upon theoretical considerations alone (Trounstine, 2010). Notably, Tausanovitch and Warshaw (2014) demonstrate that the responsiveness of elected officials at the local level is undermined because municipal voters are considered to be sensitive to the budgetary investments and changes made during the mandate of the elected official.

A debate similarly exists on the topic of accountability at the municipal level. For Elmendorf and Schleicher (2012), voters take little account of the performance of local officials, namely because municipal politics is often characterized by a lack of readily available information. Such a lowinformation context favours incumbents since voters tend to simply vote for the candidates they know the most about (Oliver and Ha, 2007). Thus, voters' choices veer to the name of the representative they know (usually the incumbent), which leads to low rates of turnover of representatives (Trounstine, 2008). However, analysis of citizens' evaluations of municipal performance show there is no advantage to incumbents who perform well (Boyne et al., 2009). Nevertheless, the probability of being re-elected is greatly reduced when performance was considered weak, and becomes practically zero when it is considered poor. Researchers have also identified a link between public spending's electoral cycle and the re-election of local governments. Specifically, increased spending ahead of elections favours the re-election of the outgoing municipal government (Sakurai and Menezes-Filho, 2008; Drazen and Eslava, 2010; Aidt et al., 2011; Sedmihradská et al.; 2011; Balaguer-Coll et al., 2014). 


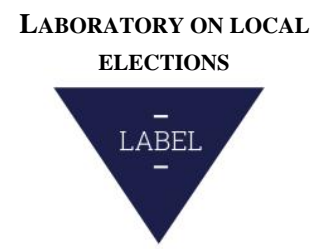

The objective of this colloquium is to explore the mechanisms of responsiveness and accountability at the municipal level. The following topics will be addressed:

$>$ The criteria that influence the decisions of local elected officials;

$>$ The influence of citizens or other stakeholders on municipal decisions;

$>$ The determinants of municipal election results;

$>$ The process of municipal election campaigns;

$>$ The performance of municipal governments.

This list is not exhaustive and all proposals related to the main theme of the call will be considered. While the perspective of this colloquium is oriented primarily to the North American context, proposals from other regions and continents are strongly encouraged.

Proposals-written in English, at minimum 500 words and at maximum 1,000 words-should be sent to Jérôme Couture (jerome.couture@pol.ulaval.ca) and Sandra Breux (sandra.breux@ucs.inrs.ca) before December 15, 2015. Proposals will be subject to a joint review by the signatories of this call. Notification of acceptance will be sent to the authors by January 15, 2016 at the latest. Authors whose proposals are accepted will have to submit their text-of a length not exceeding 8,000 words-prior to the colloquium. An edited book is planned following the colloquium.

The colloquium will take place in spring 2016 (May 17-18) and will be held at the INRS-UCS in Montreal. This event will be organized by the Laboratory on Local Elections. 